\title{
RELAÇÕES ENTRE INOVAÇÃO TECNOLÓGICA E ESTRUTURA DE CAPITAL: UM ESTUDO DE EMPRESAS BRASILEIRAS DE CAPITAL ABERTO
}

\author{
Emmanuel Sousa de Abreu \\ Mestre em Contabilidade pela Universidade Federal da Bahia - UFB \\ emmanueldeabreu@yahoo.com.br (Brasil)
}

\section{Adriano Leal Bruni}

Doutor em Administração pela Universidade de São Paulo - USP

Professor da Universidade Federal da Bahia - UFB

albruni@ufba.br (Brasil)

\section{Sonia Maria da Silva Gomes}

Doutora em Engenharia de Produção pela Universidade Federal de Santa Catarina - UFSC

Professora da Universidade Federal da Bahia - UFB

soniagomes3@gmail.com (Brasil)

\section{Roberto Brazileiro Paixão}

Doutor em Administração pela Universidade Federal da Bahia - UFB

Professor da Universidade Federal da Bahia - UFB

roberto.brazileiro@ufba.br (Brasil)

\section{RESUMO}

A captação de recursos para projetos inovadores é assunto relevante e com características peculiares já que esses tendem a terem altos níveis de intangibilidade, difícil apropriação e elevada assimetria informacional que acabam por transferir altos riscos e custos para as organizações. Nesse caminho, o presente trabalho avaliou a existência de relações entre variáveis de estrutura de capital e de inovação tecnológica no ambiente brasileiro, a partir de premissas do modelo linear de inovação. O universo da pesquisa correspondeu às empresas brasileiras de capital aberto dos ramos de Tecnologia da Informação, Químico, Telecomunicações e de Bens Industriais. Diferentes procedimentos estatísticos foram aplicados, a exemplo da análise de regressão linear múltipla e o teste não-paramétrico de Kruskal-Wallis. Para a variável input, foram encontradas correlações significativas entre os gastos em P\&D com capacidade de pagamentos, custo de capital e investimento em subsidiárias. Em relação às variáveis output, não foi possível verificar relação entre inovação e estrutura de capital. A avaliação conjunta dos resultados demonstra que parece haver uma ligação direta entre estrutura de capital e input de inovação ligado a esforços financeiros, mas que o output de inovação, a priori, ou não possui a mesma força na relação com os indicadores de estrutura de capital, ou apresentam uma relação mais tênue. Os diferentes resultados demonstram que o modelo linear serve como uma simplificação do mundo real que possibilita avaliações quantitativas parciais, mas que modelos interativos parecem ser mais coerentes ao não vincular linearmente esforço em pesquisa com resultados de processos de inovação.

Palavras-chave: Inovação tecnológica; Estrutura de capital; Pesquisa e desenvolvimento; Patentes. 


\section{INTRODUÇÃO}

O estudo da inovação requer a contribuição de diferentes áreas do saber que, muitas vezes, não se comunicam. As Finanças, como área do conhecimento, também podem oferecer respostas de como se entender a dinâmica do processo de inovação tecnológica nas organizações. A presente pesquisa buscou justamente entender a inovação de um ponto de vista específico das Finanças, analisando a estrutura de capital das empresas de acordo com o seu grau de inovação tecnológica.

Trabalhos empíricos assumem como pressuposto a existência de relação entre estrutura de capital e capacidade de investimentos em inovação, e, adicionalmente, que a primeira poderia explicar à última (Blass \& Yosha, 2003; Magri, 2009; Bond et al., 2003). O raciocínio parte de características ligadas à inovação tecnológica, como a incerteza, a intangibilidade, e a difícil apropriação que tornariam o financiamento de projetos inovativos mais arriscados, custosos e com disponibilidade de recursos limitada. Essas características alinhadas às falhas de mercado - como a assimetria informacional, risco moral e indivisibilidade - tornariam as estruturas de capital de empresas com alto esforço em inovação diferenciadas das demais. Contudo, existem outras formas de se explicar a relação entre inovação e estrutura de capital. Já que inovações podem ser capazes de abrir novas oportunidades, pode-se supor igualmente que surjam demandas por instrumentos financeiros específicos que afetariam diretamente a estrutura de capital das organizações. Este raciocínio inverteria a lógica de causa e efeito da relação (Ueda \& Hirukawa, 2003; Geronikolaou \& Papachristou, 2008).

No entanto, estudos no Brasil que tratam sobre o relacionamento entre estrutura de capital e inovação tecnológica são bastante incipientes, conforme verificado por pesquisa bibliográfica sobre os artigos científicos apresentados entre 2000 e 2012 nos anais dos encontros anuais da Associação Nacional de Pós-Graduação e Pesquisa em Administração, Anpad, e da Associação Nacional dos Programas de Pós-graduação em Ciências Contábeis, Anpcont, e em periódicos brasileiros de Administração, Contabilidade e Economia, classificados pela CAPES como QUALIS superior a B3, que listaram os temas "inovação" (innovation), "patente" (patents), "estrutura de capital" (capital structure) ou "P\&D" ( $R \& D)$ em suas palavras-chave. Também foram acessadas as seguintes bases: Biblioteca Digital Brasileira de Teses e Dissertações, Portal Periódicos da Coordenação de Aperfeiçoamento de Pessoal de Nível Superior, Capes, Scielo, Domínio Público, ProQuest, ABI/Inform complete e Business Source Complete.

Assim, estudos nacionais poderiam ajudar a esclarecer a natureza da relação entre inovação e as escolhas de financiamento. Em particular, a investigação ao nível da firma e o uso de proxies para 
Emmanuel Sousa de Abreu, Adriano Leal Bruni, Sonia Maria da Silva Gomes \& Roberto Brazileiro Paixão

ambos os comportamentos financeiros e inovativos podem fornecer uma imagem mais clara da exitência do relacionamento dessas variáveis no mercado brasileiro.

Ao mesmo tempo, para se chegar a conclusões mais robustas, os resultados obtidos em outros ambientes precisam ser confrontados com as características locais, como, por exemplo, a não participação do sistema financeiro tradicional no financiamento dessas atividades, e o comum uso de fundos e subsídios governamentais para investimentos em inovação tecnológica.

Considerando que o investimento em inovação constitui um importante fator da estrutura de capital das organizações, formulou-se o seguinte problema de pesquisa para o presente estudo: até que ponto a estrutura de capital ajuda a explicar o esforço e os resultados em inovação tecnológica de empresas brasileiras de capital aberto? A hipótese geral assuminda pelo presente estudo é de que existe relação entre estrutura de capital e inovação tecnológica.

Nesse sentido, configura-se como objetivo geral a avaliação da relação entre estrutura de capital e o processo de inovação tecnológica de empresas brasileiras. Para que se possa alcançar esse objetivo, buscou-se investigar a existência de evidências de que empresas com diferentes níveis de inovação tecnológica tendem a apresentar elementos de estrutura de capital distintos; verificar a existência de correlação entre as variáveis pré-estabelecidas de inovação e de estrutura de capital no contexto nacional; como também avaliar a capacidade dessas variáveis na predição de indicadores de inovação tecnológica.

Para operacionalização da pesquisa foram utilizados dados de empresas brasileiras de capital aberto dos ramos de Tecnologia da Informação, Químico, Telecomunicações e de Bens Industriais, e diferentes procedimentos estatísticos foram aplicados, a exemplo da análise de regressão linear múltipla e o teste não-paramétrico de Kruskal-Wallis.

Este artigo encontra-se dividido em outras quatro seções, além da presente introdução. A segunda seção apresenta a fundamentação teórica. A terceira discute os procedimentos metodológicos. A quarta aborda a análise dos resultados. Por fim, a quinta e última seção apresenta as considerações finais.

\section{FUNDAMENTAÇÃO TEÓRICA}

Revista de Administração e Inovação, São Paulo, v.12, n.1, p.326-350, jan./mar. 2015. 
Originalmente o conceito de inovação é utilizado para aqueles processos que causavam ruptura no sistema econômico, contudo os conceitos schumpeterianos, notoriamente os de inovações incremenais, foram absorvidos pelos atuais conceitos de inovação tecnológica, inclusive pela própria legislação brasileira. A título de exemplo, a Lei n ${ }^{\circ} 11.196$ (2005), no parágrafo $1^{\circ}$ do art. 17, estabelece como “(...) inovação tecnológica a concepção de novo produto ou processo de fabricação, bem como a agregação de novas funcionalidades ou características (...)".

Neste mesmo caminho, a OECD (2006) considera que uma inovação tecnológica de produto, serviço ou processo tenha sido implementada se a mesma tiver sido introduzida no mercado (inovação de produto), ou utilizada no processo de produção (inovação de processo).

Importante destacar ainda que existem diferentes modelos que buscam traduzir o processo de inovação nos sistemas econômicos. Com base em Rothwell (1994) e Tidd, Bessant e Pavit (2005), pode-se detacar os seguintes modelos de processo de inovação que se configuram em gerações: Modelo Linear ( $1^{\mathrm{a}}$ e $2^{\mathrm{a}}$ Geração), Modelo Acoplado ( $3^{\mathrm{a}}$ Geração) e Modelo Interativo (4 ${ }^{\mathrm{a}}$ e $5^{\mathrm{a}}$ Geração).

A análise efetuada pela presente pesquisa é feita a partir dos conceitos de um modelo linear, no qual o processo de desenvolvimento, produção e comercialização de novas tecnologias são interpretados por meio de uma sequência de linearmente definida. Dentro desse modelo, parte-se do pressuposto que o esforço em P\&D geraria produtos inovadores, o que permite avaliar objetivamente as relações entre inputs e outputs do processo de inovação com a estrutura de capital das empresas.

Teoricamente, a literatura econômica e de finanças identifica algumas características que tornam a atividade inovativa singular. Essas características se originam, em suma, na incerteza, no fator moral e na indivisibilidade da produção e no consumo da informação originada da inovação.

Arrow (1962) enfatizou o caráter intangível e de difícil apropropriação do produto gerado pela inovação, ao exemplificar a impossibilidade de se monopolizar algo como a informação gerada pelo processo inovativo. Para o autor, apesar de existirem instrumentos legais (patentes, por exemplo) que tornam a informação em parte apropriável, o produto gerado só seria relativamente monopolizado, pois o conhecimento gerado seria automaticamente compartilhado com a sua utilização.

A assimetria informacional e a incerteza são outras características abordadas por Arrow (1962) para diferenciar o investimento em inovação dos outros investimentos convencionais. Para o autor, quanto mais distante o processo inovativo se encontra de ser utilizado em produtos tangíveis (commodities), mais difícil seria apropriação de seus produtos e, assim, mais o seu valor seria subavaliado.

Revista de Administração e Inovação, São Paulo, v.12, n.1, p.326-350, jan./mar. 2015. 
Emmanuel Sousa de Abreu, Adriano Leal Bruni, Sonia Maria da Silva Gomes \& Roberto Brazileiro Paixão

Devido às condicões de incerteza e de assimetria descritas acima, Arrow (1962) identifica o aspecto moral como outra falha encontrada nos financiamentos a processos inovativos. Em outras palavras, devido à assimetria e à incerteza sobre os atributos do produto a ser gerado, torna-se também de difícil observação os resultados alcançados pelo agente que realiza os investimentos.

Pode-se, em suma, destacar as seguintes características da inovação tecnológica: (a) incerteza, (b) intangibilidade, e (c) difícil apropriação. Essas características se somam as falhas de mercado existentes em processos de financiamento à inovação que são de difícil superação, sendo as principais: a assimetria informacional, o risco moral e a indivisibilidade.

Tendo em vista as características elencadas do processo inovativo, muitos fatores poderiam teoricamente dificultar o seu desenvolvimento. A relevância desses fatares é tão expressiva que trabalhos como os de Madrid-Guijarro, Garcia e Van Auken (2009), Kaufmann e Tödtling (2002) e Radas e Bozic (2009) chegam a elencar as restrições financeiras como as principais barreiras à inovação nas empresas. O Quadro 1 apresenta um resumo com alguns dos principais estudos que evidenciam a relação entre inovação e estrutura de capital.

\begin{tabular}{|c|c|c|}
\hline Autor & Ano & Mercado Analisado e Principal Evidência de Suporte para a Pesquisa \\
\hline $\begin{array}{l}\text { Himmelberg e } \\
\text { Petersen }\end{array}$ & 1994 & $\begin{array}{l}\text { Mercado: pequenas empresas - indústria de alta tecnologia. } \\
\text { Evidência: Correlação positiva entre investimento em P\&D e financiamento via } \\
\text { recursos internos. }\end{array}$ \\
\hline Brown & 1997 & $\begin{array}{l}\text { Mercado: empresas inglesas. } \\
\text { Evidência: Resultados Empresas inovadoras possuem maiores restrições } \\
\text { financeiras do que aquelas que não foram consideradas inovadoras. }\end{array}$ \\
\hline Harhoff & 1998 & $\begin{array}{l}\text { Mercado: Pequenas e grandes empresas alemãs. } \\
\text { Evidência: Correlação positiva fraca, mas significativa, entre investimento em } \\
\text { P\&D e financiamento via recursos internos (fluxo de caixa). }\end{array}$ \\
\hline $\begin{array}{l}\text { Klette e } \\
\text { Griliches }\end{array}$ & 2000 & $\begin{array}{l}\text { Mercado: Empresas norueguesas de alta tecnologia. } \\
\text { Resultado: Não encontraram diferenças entre empresas inovadoras e não } \\
\text { inovadoras. }\end{array}$ \\
\hline $\begin{array}{l}\text { Hovakimian et } \\
\text { al. }\end{array}$ & 2001 & $\begin{array}{l}\text { Mercado: Diversos (Standard \& Poor's) } \\
\text { Alavancagem tende a ser relação negativa com os gastos em P\&D. }\end{array}$ \\
\hline Hall & 2002 & $\begin{array}{l}\text { Mercado: pequenas empresas inglesas com grande investimento em P\&D. } \\
\text { Evidência: Pequenas empresas, com alto grau de P\&D enfrentam um maior } \\
\text { custo de capital do que seus concorrentes de grande porte ou de empresas de } \\
\text { menor porte, mas menos inovadoras. Encontrada também uma hierarquia de } \\
\text { financiamento (Teoria do Pecking Order). }\end{array}$ \\
\hline Bond et al. & 2003 & $\begin{array}{l}\text { Mercado: empresas alemãs e inglesas. } \\
\text { Evidência: correlação entre recursos internos (fluxo de caixa) e o fato da } \\
\text { empresa realizar ou não P\&D. }\end{array}$ \\
\hline Blass e Yosha & 2003 & $\begin{array}{l}\text { Mercado: empresas israelenses de capital aberto. } \\
\text { Padrões de financiamento de empresas intensivas em P\&D diferiam das } \\
\text { empresas que não foram consideradas envolvidas em P\&D. Os investimentos } \\
\text { em P\&D tenderiam a ser financiados com recursos gerados internamente. }\end{array}$ \\
\hline $\begin{array}{c}\text { Ueda e } \\
\text { Hirukawa }\end{array}$ & 2003 & $\begin{array}{c}\text { Mercado: empresas estadunidenses. } \\
\text { Evidência: Encontrada relação causal de inovação para endividamento. O }\end{array}$ \\
\hline
\end{tabular}

Revista de Administração e Inovação, São Paulo, v.12, n.1, p.326-350, jan./mar. 2015. 


\begin{tabular}{|c|c|c|}
\hline & & $\begin{array}{l}\text { achado empírico é justificado pela idéia que muitas empresas se endividariam } \\
\text { em virtude de possibilidades de investimentos inovativos, ou seja, elas apenas } \\
\text { captariam recursos se houvesse a viabilidade de investimentos em inovação. }\end{array}$ \\
\hline Aghion et al. & 2004 & $\begin{array}{l}\text { Mercado: empresas de capital aberto inglesas. } \\
\text { Evidência: Encontrada relação não-linear. Empresas que relataram P\&D tendem } \\
\text { a se endividar mais do que as empresas com inexistência de P\&D. Contudo, } \\
\text { analisadas apenas as empresas com P\&D, a tendência foi inversa, com o } \\
\text { aumento da intensidade de P\&D houve uma diminuição da alavancagem. }\end{array}$ \\
\hline Magri & 2009 & $\begin{array}{l}\text { Mercado: pequenas e grandes empresas inovadoras italianas. } \\
\text { Pequenas empresas inovadoras se endividam menos e tendem a utilizar mais } \\
\text { recursos financeiros próprios, quando comparadas com grandes empresas. A } \\
\text { relação não foi encontrada em grandes empresas. }\end{array}$ \\
\hline Bartoloni & 2010 & $\begin{array}{l}\text { Mercado: empresas italianas. } \\
\text { Restrições financeiras aumentam com o esforço de inovação. Hierarquia de } \\
\text { financiamento (Teoria do Pecking Order), empresas seriam menos endividadas, } \\
\text { à medida que se aumenta a sua rentabilidade operacional, porém, de outro lado, } \\
\text { defende que o uso de financiamento externo aumenta com o esforço de } \\
\text { inovação. O trabalho também verifica a existência de restrições de crédito os } \\
\text { quais afetaram mais pequenas empresas inovadoras quando comparadas com } \\
\text { empresas maiores. }\end{array}$ \\
\hline
\end{tabular}

\section{Quadro 1- Síntese de trabalhos sobre inovação e estrutura de capital.}

Fonte: Elaborado pelos autores, 2013.

É importante destacar que grande parte das pesquisas avaliadas justificam seus achados, principalmente, pela natureza intangível dos investimentos inovativos, que tende a gerar falhas de mercado, como informação assimétrica e risco moral. Assim, as empresas inovadoras teriam sérias restrições financeiras, como dificuldade de acesso a recursos externos ou com esses a elevados custos de captação. A forma de financiamento, porém, depende de diversas outras questões, como mercado de atuação, porte da empresa, nível de inovação tecnológica, entre outras.

As pesquisas nacionais que relacionam, especificamente, inovação tecnológica com a estrutura de capital de empresas brasileiras são incipientes. No entanto, existem estudos que se aproximam da matéria ao tratarem de aspectos como restrições financeiras às empresas inovadoras, ativos intangíveis, determinantes da estrutura de capital ou, ainda, ao abordarem o alcance de políticas públicas de incentivo à inovação que tentam amenizar as restrições impostas a este tipo de investimento. Apresentar alguns dos resultados desses estudos ajuda a entender e elencar peculiaridades existentes no Brasil e fundamentar teoricamente algumas escolhas e interpretações feitas na presente pesquisa.

Primeiramente, uma característica fundamental do ambiente brasileiro para a análise do presente artigo é trazida por Costa e Deos (2002) que defenderam que a história da economia brasileira mostraria um rearranjo, de acordo com a conformação de cada padrão de desenvolvimento, de uma estrutura financeira tripolar, constituída de setor externo, setor público e setor financeiro privado nacional. Assim, os autores atribuem ao setor financeiro brasileiro o papel restrito de financiamento das necessidades de capital de giro, e ao setor público e externo o papel de financiar os investimentos a 
Emmanuel Sousa de Abreu, Adriano Leal Bruni, Sonia Maria da Silva Gomes \& Roberto Brazileiro Paixão

prazo maior. Podem-se destacar, de acordo com Costa e Deos (2002), duas alternativas de financiamento no Brasil:

a) financiamento indireto via intermediários financeiros, empréstimos em moeda estrangeira, mecanismo cambial, tributação ou qualquer outro instrumento governamental; e

b) financiamento direto (ou autofinanciamento) via investimento direto externo e reinversão de lucro da indústria, acumulado em função de redistribuição da renda entre os setores industrial e agrícola implícita em seus termos de troca, do aumento da produtividade acima dos salários reais e ampliado por remarcação de preços em ritmo superior aos custos.

Em outro caminho, Nakamura et al. (2007) chegaram à conclusão de que o comportamento dos tomadores de decisão das empresas brasileiras seguiria a lógica de escolha de flexibilidade e controle (Pecking Order), mas com uma dinâmica de ajuste de grau de endividamento ótimo de curto prazo (Trade-off).

A existência de restrição ao crédito para empresas brasileiras que reportaram gastos em P\&D foi encontrada por Jensen, Menezes-Filho e Sbragia (2004). Os resultados encontrados pelos autores, em suma, foram: quanto maior o faturamento bruto e menor o patrimônio líquido, maior a tendência de a empresa investir em P\&D; a variável lucro líquido sobre faturamento não se mostrou significante, sugerindo que o caixa além de não influenciar na decisão sobre os gastos em $\mathrm{P} \& \mathrm{D}$, também não influencia sua magnitude.

Já Kayo (2002) analisa indiretamente o aspecto inovativo das firmas, avaliando as diferenças de estrutura de capital e de risco entre empresas tangível e intangível-intensivas. Os resultados da pesquisa mostram que a estrutura de capital parece ser o fator mais importante na diferenciação entre os dois tipos de empresas. Um pouco mais tarde, Kayo, Teh e Basso (2004) aproximam-se parcialmente do objeto do presente artigo ao avaliar as relação entre estrutura de capital e variáveis representativas de ativos intangíveis, no caso representadas por quantidade de patentes, tempo médio de vida das patentes e quantidade de marcas. Os resultados da regressão stepwise indicaram que a quantidade de patentes é significativa e negativamente relacionada com o endividamento, corroborando, segundo os autores, com a teoria. Desta forma, empresas com maior intensidade em ativos intangíveis de inovação (representada pelas patentes) apresentariam baixos níveis de endividamento.

A relação entre patentes e endividamento também foi avaliado por Crocco et al. (2008) a partir de microdados de variáveis bancárias e seu relacionamento com quantidade de patentes. Os autores encontram indícios de que melhores indicadores financeiros (crédito, depósito e inserção bancária)

Revista de Administração e Inovação, São Paulo, v.12, n.1, p.326-350, jan./mar. 2015. 
aumentam a probabilidade de sustentação da inovação e de que a alta concentração das esferas tecnológica e financeira corrobora a forte relação entre inovação, crédito e espaço.

Outra característica importante do ambiente brasileiro é trazida por Valle (2008) que traz resultados que indicam que: as fontes ou linhas diferenciadas de recursos e as linhas em moeda estrangeira tiveram participação significativa no nível de endividamento de empresas brasileiras, a inclusão do acesso a estas fontes ou linhas juntamente com variáveis clássicas (tamanho, tangibilidade etc.) nos modelos de determinação do nível de endividamento contribuiu para o entendimento da estrutura de capital das empresas brasileiras amostradas.

Já Meirelles (2008) verificou no Brasil uma larga predominância das inovações que correspondem ao aprimoramento de produtos ou processos já existentes na empresa, ou de inovações para a própria empresa, mas já existentes no setor, e que o investimento nacional em P\&D é relativamente baixo, estando a execução de P\&D associada mais ao governo. Da mesma forma que, dentre as diferentes fontes de financiamento para inovação, o percentual de recursos próprios utilizados no financiamento das atividades inovativas é maior, principalmente no caso das atividades de $\mathrm{P} \& \mathrm{D}$, em comparação com o financiamento dos investimentos em geral.

\section{PROCEDIMENTOS METODOLÓGICOS}

O universo da presente pesquisa correspondeu às 53 empresas relacionadas nos segmentos de Tecnológia da Informação, Químico, Telecomunicações (telefonia fixa e móvel) e de Bens Industriais da BM\&BOVESPA listados na data base de dezembro de 2012.

Foi determinante para a seleção dos setores e subsetores de atuação o potencial índice de inovação comumente existente nos respectivos segmentos. A escolha dos setores também procurou fornecer uma identificação mais objetiva entre os segmentos de atuação das empresas, e permitir uma visão homogênea sobre empresas. Ou seja, fornecer um conjunto de empresas que, embora tivessem atividades diferentes, atuassem em estágios similares da cadeia produtiva ou com produtos relacionados e, assim, tendessem a responder de forma semelhante às condições econômicas.

Para a operacionalização da pesquisa foram coletados três conjuntos diferentes de dados, com formas de captação específica:

a) Índices de estrutura de capital: obtenção das informações de forma secundária por consulta direta dos índices de estrutura de capital disponibilizados pelo sistema operacional da base

Revista de Administração e Inovação, São Paulo, v.12, n.1, p.326-350, jan./mar. 2015. 
de dados da Economatica. Os indicadores são obtidos por meio das demonstrações consolidadas das instituições.

b) Gastos com P\&D: dados obtidos de forma primária por meio das demonstrações financeiras padronizadas das instituições abrangidas pelo universo da pesquisa e que são disponibilizadas no site da BM\&FBOVESPA. Ou seja, os gastos em P\&D foram obtidos diretamente por meio da demonstração de resultado e por meio das notas explicativas. Foram utilizadas as demosntrações consolidadas dos grupos de empresas. Residualmente, em virtude de nem todas as empresas divulgarem em suas demonstrações os gastos em P\&D e com o objetivo de se aumentar a amostragem, foram solicitadas às empresas que não divulgaram os dados, as informações resíduais, sendo que seis forneceram os dados para a pesquisa.

c) Quantidade de solicitação de patentes: dados obtidos de forma secundária, junto à base de dados do Instituto Nacional da Propriedade Industrial (INPI). O critério utilizado na pesquisa foi a quantidade anual de pedidos de patente por depositante.

A coleta dos dados gerou duas amostras finais: uma referente à relação dos indicadores de estrutura de capital com o indicador de gastos em P\&D e outra aos indicadores de estrutura de capital com os dados de patentes. Do universo estabelecido, as amostras consideraram apenas as empresas para as quais foi possível se obter dados completos de 2009 a 2012. A Figula 1 ilustra o processo de formação das amostras.

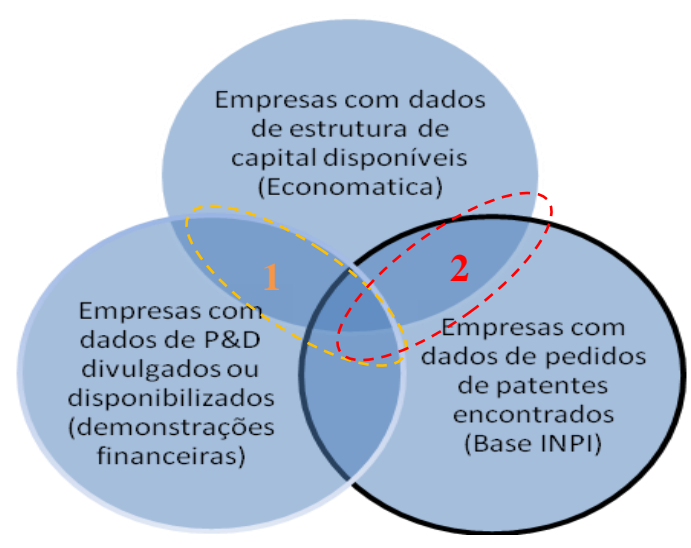

Figura 1 - Formação das Amostras

Fonte: Elaborada pelos autores, 2013

Como se pode observar na Figura 1, o universo inicial é representado pelo conjunto total dos três circulos e as amostras foram formadas pela interseção dos circulos referentes aos dados de inovação tecnológica com os de estrutura de capital, formando as amostras 1 e 2 , representadas pelas elipses tracejadas. 
Foram utilizadas para a medição do processo de inovação tecnológica duas proxies derivadas dos dados de gastos em P\&D e de solicitações de patentes por empresas. Já para os indicadores de estrutura de capital, foram escolhidos índices financeiros de acordo com os estudos anteriores realizados e disponibilizados pelo sistema Economática. O quadro 2 apresenta as equações das variáveis utilizadas com respectivas explicações.

\begin{tabular}{|c|c|}
\hline Fórmula & Descrição \\
\hline Ped $=\frac{\text { Gastos_em_P\&D }}{\text { Faturamento }} .100$ & $\begin{array}{l}\text { Busca traduzir o esforço monetário por inovação (variável de } \\
\text { entrada) da empresa e, ao mesmo tempo, tem o efeito de compensar } \\
\text { o efeito do porte da empresa. }\end{array}$ \\
\hline$P a t=\frac{n^{\circ} d e_{-} \text {solicitações_de_patentes }}{\text { Faturamento }} \cdot 10^{6}$ & $\begin{array}{l}\text { usca quatificar o resultado do processo de inovação tecnológica } \\
\text { output) e, também, compensa o efeito do porte da empresa. }\end{array}$ \\
\hline Dbat $=\frac{\text { Dívida_Total_Bruta }}{\text { Ativo_Total }} .100$ & $\begin{array}{l}\text { Endividamento Geral (\%): Demonstra o comportamento da } \\
\text { estrutura financeira da companhia, indicando a proporção do ativo } \\
\text { total financiado pelos recursos provenientes de terceiros. Esse } \\
\text { índice buscará, dessa forma, evidenciar a política de obtenção de } \\
\text { recursos das empresas. Como está expresso em porcentagem, o } \\
\text { índice demonstra quantos por cento do financiamento do ativo } \\
\text { ocorre via captação com recursos próprios ou de terceiros. }\end{array}$ \\
\hline$E b d b=\frac{E b i t(\text { LAJIR })}{\text { Divida_Total_Bruta }} .100$ & $\begin{array}{l}\text { Cobertura da dívida (\%): Relação entre o EBIT (Earning Before } \\
\text { Interest, } \operatorname{Tax}^{1}{ }^{1} \text { ) e a dívida total bruta. Esse indicador evidencia a } \\
\text { capacidade de pagamento das dívidas com terceiros pela } \\
\text { companhia. }\end{array}$ \\
\hline Dcdt $=\frac{\text { Dívida_Curto } \_ \text {prazo }}{\text { Dívida_Total } \_ \text {Bruta }} .100$ & $\begin{array}{l}\text { Composição da dívida (\%): Relação entre o passivo de curto prazo } \\
\text { da empresa e o passivo total. Ou seja, o índice evidencia qual o } \\
\text { percentual de passivo de curto prazo é usado na captação de } \\
\text { recursos de terceiros, demonstrando se a empresa concentra seu } \\
\text { endividamento no curto ou no longo prazo. }\end{array}$ \\
\hline$C c t=\frac{\text { Despesas_financeiras }}{\text { Total_emp_fin }} .100$ & $\begin{array}{l}\text { Custo do Capital de Terceiros (\%): Relação entre as despesas } \\
\text { financeiras com o total de empréstimos da companhia. Representa a } \\
\text { remuneração média que a entidade paga para a instituição } \\
\text { financeira nos empréstimos obtidos. De outro modo, o indicador } \\
\text { evidencia o nível de preço pago pela captação com recursos de } \\
\text { terceiros. }\end{array}$ \\
\hline$I v p l=\frac{\text { Investimento_subs_outros }}{\text { PatrimônioLíquido }} .100$ & $\begin{array}{l}\text { Grau de investimento (\%): Relação entre os investimentos em } \\
\text { subsidiárias e o patrimônio líquido da companhia. Ressalta a } \\
\text { relevância da participação, direta ou indireta da companhia em } \\
\text { outras empresas. Ou seja, o indicador evidencia o nível de } \\
\text { participação da empresa em outras companhias. }\end{array}$ \\
\hline
\end{tabular}

Quadro 2 - Descrição das variáveis analisadas no presente estudo.

Fonte: Elaborado pelos autores, 2013.

Tanto os gastos com pesquisa e desenvolvimento como a quantidade de patentes são métricas sugeridas pelo Manual Frascat da OCDE e pelo Manual de Oslo, primeira edição, e, mais

\footnotetext{
${ }^{1}$ Lucro antes dos juros, imposto de renda (LAJIR).
} 
Emmanuel Sousa de Abreu, Adriano Leal Bruni, Sonia Maria da Silva Gomes \& Roberto Brazileiro Paixão

especificamente, pelo modelo proposto pela Oficina Estatística da Comunidade Européia EUROSTAT, a terceira versão da Community Innovation Survey (CIS III) 1998 - 2000.

O gasto em P\&D é o mais tradicional indicador de insumo de inovação, ou seja, é uma métrica utilizada para avaliar o esforço na etapa input. Esta métrica é altamente utilizada pela literatura (Tidd, 2001; Motohashi, 1998; Li \& Atuahene-Gima, 2001; Walker et al., 2002; Koschatzky, 1999). Já o número de patentes é uma métrica de resultado, ou seja, utilizada para avaliar o esforço na etapa output. O número de patentes também é uma métrica usualmente utilizada pela literatura (Tidd, 2001; Motohashi, 1998; Walker et al., 2002; Kayo et al., 2004).

Dez hipóteses instrumentais foram formadas, a partir do confronto entre as duas métricas de inovação tecnológica e as cinco métricas de estrutura de capital. Para a validadação das hipóteses instrumentais foram utilizadas duas ferramentas estatísticas distintas. As hipóteses instrumentais e as ferramentas de análise estão resumidas no Quadro 3.

\begin{tabular}{|c|c|c|c|}
\hline & Hipóteses Instrumentais & $\begin{array}{l}\text { Procedimento } \\
\text { Estatístico }\end{array}$ & Justificativa \\
\hline H1 & $\begin{array}{l}\text { Existe relação entre endividamento e investimentos } \\
\text { em inovação tecnológica. }\end{array}$ & \multirow{5}{*}{$\begin{array}{c}\text { Correlação e } \\
\text { Regressão } \\
\text { Linear Múltipla }\end{array}$} & \multirow{5}{*}{$\begin{array}{c}\text { Verificar o } \\
\text { relacionamento e a } \\
\text { capacidade de } \\
\text { predição entre as } \\
\text { variáveis. } \\
\text { Pressupostos } \\
\text { paramétricos } \\
\text { satisfeitos. }\end{array}$} \\
\hline $\mathrm{H} 2$ & $\begin{array}{l}\text { Existe relação entre capacidade de pagamentos de } \\
\text { dívida e investimentos em inovação tecnológica. }\end{array}$ & & \\
\hline $\mathrm{H} 3$ & $\begin{array}{l}\text { Existe relação entre composição de dívida e } \\
\text { investimentos em inovação tecnológica. }\end{array}$ & & \\
\hline $\mathrm{H} 4$ & $\begin{array}{c}\text { Existe relação entre custo do capital de terceiros e } \\
\text { investimentos em inovação tecnológica. }\end{array}$ & & \\
\hline $\mathrm{H} 5$ & $\begin{array}{l}\text { Existe relação entre grau de participação em } \\
\text { subsidiárias e investimentos em inovação tecnológica. }\end{array}$ & & \\
\hline H6 & $\begin{array}{l}\text { Existe relação entre endividamento e geração de } \\
\text { patentes. }\end{array}$ & \multirow{5}{*}{$\begin{array}{l}\text { Teste de } \\
\text { Kruskal-Wallis }\end{array}$} & \multirow{5}{*}{$\begin{array}{c}\text { Verificar a } \\
\text { existência de } \\
\text { diferenças } \\
\text { significativas entre } \\
\text { as empresas com } \\
\text { diferentes índices de } \\
\text { patentes. } \\
\text { Pressupostos } \\
\text { paramétricos não } \\
\text { satisfeitos. }\end{array}$} \\
\hline $\mathrm{H} 7$ & $\begin{array}{l}\text { Existe relação entre capacidade de pagamentos de } \\
\text { dívida e geração de patentes. }\end{array}$ & & \\
\hline H8 & $\begin{array}{l}\text { Existe relação entre composição de dívida e geração } \\
\text { de patentes. }\end{array}$ & & \\
\hline H9 & $\begin{array}{l}\text { Existe relação entre custo do capital de terceiros e } \\
\text { geração de patentes. }\end{array}$ & & \\
\hline $\mathrm{H} 10$ & $\begin{array}{c}\text { Existe relação entre grau de participação em } \\
\text { subsidiárias e geração de patentes. }\end{array}$ & & \\
\hline
\end{tabular}

Quadro 3 - Hipóteses instrumentais e respectivos procedimentos estatísticos.

Fonte: Elaborado pelos autores, 2013.

Ressalta-se que, a priori, os procedimentos estatísticos escolhidos para a validação das hipóteses envolveram o cálculo de coeficientes de correlação entre as variáveis e a realização de testes estatísticos de regressão linear múltipla entre as variáveis de inovação tecnógica e as de estrutura de capital. Contudo, como será demonstrado na Seção 3, os dados referentes aos indicadores de patentes violaram hipóteses paramétricas, não tendo sido possível a normalização da distribuição dos dados, por

Revista de Administração e Inovação, São Paulo, v.12, n.1, p.326-350, jan./mar. 2015. 
meio da transformação dos dados (logarítimica, radiciação, etc.). Por isso, foi necessário se utilizar um teste estatístico não-paramétrico (Kruskal-Wallis) para avaliar a possível relação entre os dados de indicadores de estrutura de capital e os dados referentes ao indicador de patentes.

\section{ANÁLISE E INTERPRETAÇÃO DOS RESULTADOS}

Tendo em vista que a avaliação dos dados referentes à amostra para avaliação dos indicadores de $\mathrm{P} \& \mathrm{D}$ apresentou os pressupostos para a execução de testes paramétricos, foram realizadas a análise das correlações e construido um modelo de regressão linear múltipla entre as variáveis. A Tabela 1 apresenta a matriz de correlações cruzadas que, primeiramente, indica os valores dos coeficientes de correlação de Pearson entre cada par de variáveis.

Tabela 1- Correlações cruzadas.

\begin{tabular}{|c|c|c|c|c|c|c|c|}
\hline & & Ped & Dbat & Ebdb & Dcdt & Cct & Ivpl \\
\hline & Ped & 1,000 &, 106 &, 421 &,- 128 &,- 447 &,- 417 \\
\hline & Dbat &, 106 & 1,000 &,- 491 &,- 250 &,- 568 &, 393 \\
\hline & Ebdb & $\mathbf{4 2 1}$ &,- 491 & 1,000 &, 151 &, 211 &,- 159 \\
\hline & Dcdt &,- 128 &,- 250 &, 151 & 1,000 &, 440 &,- 368 \\
\hline & Cct & $\mathbf{- , 4 4 7}$ &,- 568 &, 211 &, 440 & 1,000 &, 090 \\
\hline & Ivpl & $\mathbf{- , 4 1 7}$ &, 393 &,- 159 &,- 368 &, 090 & 1,000 \\
\hline & Ped &. &, 329 &, 032 &, 295 &, 024 &, 034 \\
\hline & Dbat &, 329 &. &, 014 &, 144 &, 004 &, 043 \\
\hline & Ebdb & $\mathbf{, 0 3 2}$ &, 014 &. &, 262 &, 186 &, 252 \\
\hline & Dcdt &, 295 &, 144 &, 262 &. &, 026 &, 055 \\
\hline & Cct & $\mathbf{, 0 2 4}$ &, 004 &, 186 &, 026 &. &, 353 \\
\hline & Ivpl & $\mathbf{, 0 3 4}$ &, 043 &, 252 &, 055 &, 353 &. \\
\hline & & 20 & 20 & 20 & 20 & 20 & 20 \\
\hline
\end{tabular}

Fonte: Elaborada pelos autores, 2013.

As variáveis Dbat (Endividamento geral) e Dcdt (Composição da dívida) apresentaram baixa correlação, com coeficientes de Pearson iguais a 0,106 e 0,128 , respectivamente. A correlação dos indicadores ainda foram não significativas estatisticamente com $p$ bem acima de 0,05 (0,329 e 0,295, respectivamente).

Contudo, foram encontradas correlações significativas entre a variável de gastos em P\&D (Ped) e as variáveis Ebdb (Cobertura da dívida), custo do capital de terceiros (Cct) e grau de investimento (Ivpl). A primeira apresentou uma correlação positiva com Ped $(r=0,421)$ indicando que empresas com maior percentual de gastos em P\&D, tendem a apresentar uma maior alavancagem. Já Cct e Ivpl 
Emmanuel Sousa de Abreu, Adriano Leal Bruni, Sonia Maria da Silva Gomes \& Roberto Brazileiro Paixão

apresentaram correlações negativas com a variável Ped ( $r=-447$ e -417 , respectivamente), o que indica que as empresas com maiores percentuais de gastos em P\&D tendem a ter menores custos de endividamento e menores investimentos em outras companhias.

Tendo como objetivo avaliar a capacidade de predição da variável Ped pelas variáveis de estrutura de capital foi também realizada uma regressão linear do tipo Stepwise. Essa metodologia reavalia todos os regressores inseridos inicialmente no modelo a partir das estatísticas F (parciais), possibilitando que um regressor adicionado anteriormente possa se tornar redundante em virtude da nova relação.

Destaca-se que o indicador Ivpl (Grau de Investimento), apesar de ter tido uma correlação significante, foi excluída dos dois modelos gerados por não agregar um caráter de explicação aos modelos formados com um regressor (Cct) e com dois regressores (Ebdb e Cct). A exclusão dos demais regressores já era esperada, haja vista a correlação com a variável Ped ter se mostrado não significativa.

Cabe esclarecer ainda que foi identificado um único caso de resíduo anormal identificado na amostra. Os dados, dessa forma, apresentaram apenas 5\% de resíduo padronizado fora do limite, ajustando-se bem ao modelo. A título de informação, o resíduo foi originado dos dados da empresa Totvs S.A. que apresentou um indicador Ped médio no período de análise de 12,82. Ou seja, a empresa em média gastou $12,82 \%$ do faturamento em P\&D, bem acima dos indicados pelas outras empresas e que poderia introduzir tendeciosidade nos modelos de regressão e por isso foi tratada como resíduo anormal.

Apresenta-se na Tabela 2 um resumo dos principais dados sobre os modelos, informando sobre a sua eficácia para a previsão da variável Ped (outcome). O modelo 1 se refere ao primeiro estágio da hierarquia quando apenas o indicador Cct (Custo do Capital de Terceiros) é utilizado como previsor. Já o modelo 2 utiliza, além do indicador Cct, o Ebdb (Cobertura da dívida).

Tabela 2 - Resumo dos Modelos (Variável dependente: Ped)

\begin{tabular}{|c|c|c|c|c|}
\hline Modelo & $\boldsymbol{r}$ & $\boldsymbol{r}$ Quadrado & $\begin{array}{c}\boldsymbol{r} \text { Quadrado } \\
\text { Ajustado }\end{array}$ & $\begin{array}{c}\text { Erro Padrão da } \\
\text { Estimativa }\end{array}$ \\
\hline 1 &, $447(\mathrm{a})$ &, 200 &, 155 & 2,66464955 \\
\hline 2 &, $691(\mathrm{~b})$ &, 478 &, 416 & 2,21489888 \\
\hline
\end{tabular}

Fonte: Elaborada pelos autores a partir dos dados da pesquisa, 2013

a Previsor: (Constante), Cct.

b Previsores: (Constante), Cct, Ebdb

Revista de Administração e Inovação, São Paulo, v.12, n.1, p.326-350, jan./mar. 2015. 
Para facilitar a análise dos dados, também são fornecidos na Tabela 3 os valores padronizados de $b($ Beta $)$ que indicam as alterações no número de desvios padrão na variável Ped em decorrência da alteração de um desvio padrão nas variáveis Cct e Ebdb. Desta forma os valores Beta são todos mensurados em unidades de desvios-padrão, possibilitando a comparação entre as variáveis diretamente. Como se pode perceber, os valores dos coeficientes padronizados Beta dos previsores (0,561 e 0,540), desconsiderando a relação positiva ou negativa, estão bem próximos, confirmando a proximidade de importância para o modelo, já verificada por meio das estatísticas $t$ e dos seus respectivos níveis de significância.

Tabela 3 - Coeficientes, Correlações e Colinearidade (Variável Dependente: Ped)

\begin{tabular}{|c|c|c|c|c|c|c|}
\hline \multicolumn{2}{|c|}{ Modelo } & \multicolumn{3}{c|}{ Correlações } & \multicolumn{2}{c|}{$\begin{array}{c}\text { Estatísticas de } \\
\text { Colinearidade }\end{array}$} \\
\hline & & $\begin{array}{c}\text { De ordem } \\
\text { Zero }\end{array}$ & Parcial & Parte & Tolerância & VIF \\
\hline 1 & (Constante) & & & & & \\
\hline & Cct &,- 447 &,- 447 &,- 447 & 1,000 & 1,000 \\
\hline 2 & (Constante) & & & & & \\
\hline & Cct &,- 447 &,- 604 &,- 548 &, 955 & 1,047 \\
\hline & Ebdb &, 421 &, 589 &, 527 &, 955 & 1,047 \\
\hline
\end{tabular}

Fonte: Elaborada pelos autores a partir dos dados da pesquisa, 2013.

Após a análise dessas estatísticas (correlações de ordem zero e parciais e colinearidade), podese indicar a seguinte equação de regressão linear múltipla que relaciona os indicadores Cct (Custo do capital de terceiros) e Ebdb (Cobertura da dívida) como previsores de Ped (Indicador de gastos em P\&D):

$$
P e d=3,434-0,119 . C c t+0,062 . E b d b
$$

Já, em termos das variáveis padronizadas, o modelo final e dado por:

$$
P e d=-0,561 . C c t+0,540 . E b d b
$$

Os coeficientes padronizados permitem simplificar a avaliação da importância de cada regressor, já que iguala as unidades de medida das variáveis e que a constante é sempre igual a zero, podendo, portanto, ser omitida. Observa-se que a padronização permite verificar que a variável do modelo que mais contribui para a variação de Ped é a Cct, porém também permite verificar que a diferença de contribuição é pequena em relação à Ebdb.

Os dados referentes aos indicadores de patentes não se mostraram normalmente distribuídos. Foi-se necessário utilizar testes não-paramétricos de Kruskal-Walls para se testar a hipótese da relação entre indicadores de estrutura de capital e o indicador de solicitação de patentes. As 22 observações 
Emmanuel Sousa de Abreu, Adriano Leal Bruni, Sonia Maria da Silva Gomes \& Roberto Brazileiro Paixão

válidas da amostra foram segmentadas em três grupos de acordo com o menor ou maior indicador de solicitações de patentes. A Tabela 4 traz um resumo das posições dos dados para cada condição estabelecida o que possibilita uma análise prévia das diferenças das posições.

Tabela 4 - Posições (ranks) médias dos indicadores de estrutura de capital.

\begin{tabular}{|c|c|c|c|}
\hline & Grupo por Indicador de Patentes & $\mathbf{N}$ & $\begin{array}{l}\text { Médias das } \\
\text { posições }\end{array}$ \\
\hline \multirow[t]{4}{*}{$\begin{array}{c}\text { Endividamento Geral } \\
\text { (Dbat) }\end{array}$} & $\begin{array}{l}\text { Empresas com baixo índice de } \\
\text { patentes }\end{array}$ & 7 & 12,43 \\
\hline & $\begin{array}{l}\text { Empresas com médio índice de } \\
\text { patentes }\end{array}$ & 7 & 12,57 \\
\hline & $\begin{array}{l}\text { Empresas com elevado índice de } \\
\text { patentes }\end{array}$ & 8 & 9,75 \\
\hline & Total & 22 & \\
\hline \multirow[t]{4}{*}{$\begin{array}{c}\text { Cobertura da dívida } \\
\text { (Ebdb) }\end{array}$} & $\begin{array}{c}\text { Empresas com baixo índice de } \\
\text { patentes }\end{array}$ & 7 & 11,29 \\
\hline & $\begin{array}{c}\text { Empresas com médio índice de } \\
\text { patentes }\end{array}$ & 7 & 10,29 \\
\hline & $\begin{array}{c}\text { Empresas com elevado índice de } \\
\text { patentes }\end{array}$ & 8 & 12,75 \\
\hline & Total & 22 & \\
\hline \multirow[t]{4}{*}{$\begin{array}{c}\text { Composição da dívida } \\
\text { (Dcdt) }\end{array}$} & $\begin{array}{c}\text { Empresas com baixo índice de } \\
\text { patentes }\end{array}$ & 7 & 9,14 \\
\hline & $\begin{array}{l}\text { Empresas com médio índice de } \\
\text { patentes }\end{array}$ & 7 & 10,00 \\
\hline & $\begin{array}{c}\text { Empresas com elevado índice de } \\
\text { patentes }\end{array}$ & 8 & 14,88 \\
\hline & Total & 22 & \\
\hline \multirow[t]{4}{*}{$\begin{array}{l}\text { Custo Cap. de Terceiros } \\
\text { (Cct) }\end{array}$} & $\begin{array}{c}\text { Empresas com baixo índice de } \\
\text { patentes }\end{array}$ & 7 & 9,71 \\
\hline & $\begin{array}{l}\text { Empresas com médio índice de } \\
\text { patentes }\end{array}$ & 7 & 14,14 \\
\hline & $\begin{array}{l}\text { Empresas com elevado índice de } \\
\text { patentes }\end{array}$ & 8 & 10,75 \\
\hline & Total & 22 & \\
\hline \multirow[t]{4}{*}{$\begin{array}{c}\text { Grau de investimento } \\
\text { (Ivpl) }\end{array}$} & $\begin{array}{c}\text { Empresas com baixo índice de } \\
\text { patentes }\end{array}$ & 7 & 14,86 \\
\hline & $\begin{array}{l}\text { Empresas com médio índice de } \\
\text { patentes }\end{array}$ & 7 & 11,71 \\
\hline & $\begin{array}{c}\text { Empresas com elevado índice de } \\
\text { patentes }\end{array}$ & 8 & 8,38 \\
\hline & Total & 22 & \\
\hline
\end{tabular}

Fonte: Elaborada pelos autores a partir dos dados da pesquisa, 2013.

Pode-se verificar que dois indicadores de estrutura de capital apresentaram um comportamento aparentemente linear das posições de acordo com o grupo de indicador de patentes (Dcdt e Ivpl) e três não apresentaram comportamento linear (Dbat, Ebdb e Cct). O indicador de composição da dívida 
apresentou um aumento mais substancial entre os grupos, variando entre os valores de 9,14, 10,00 e 14,88 do grupo com menor para o maior índice. Já o indicador do grau de investimento apresentou um decrescimento linear com a passagem entre as posições dos grupos.

Apesar das aparentes relações de crescimento ou decrescimento apontadas, o teste de KruskalWallis averiguou se as diferenças das médias das posições eram significativas estatisticamente. A significância para o indicador de endividamento geral foi de 0,584 , o de cobertura da dívida foi de 0,720, o de composição da dívida foi de 0,268 , o do custo de capital de terceiros foi de 0,639 , e o do grau de investimento foi de 0,109 . Ou seja, todos os níveis de significância foram superiores a 0,05, o que confirma a hipótese nula para o teste de igualdade das médias populacionais, não diferindo as médias entre os grupos com diferentes índices de patentes.

De outra forma, não foi possível verificar que empresas com diferentes intensidades de solicitações de patentes apresentaram diferenças significativas em suas estruturas de capital. Assim, a hipótese estabelecida na presente pesquisa de que existem relações entre o nível de saída de inovação tecnológica e a estrutura de capital das empresas não pode ser aceita. O quadro 4 sintetiza os resultados encontrados.

\begin{tabular}{|c|c|c|c|}
\hline \multicolumn{2}{|r|}{ Hipóteses Instrumentais } & $\begin{array}{c}\text { Método } \\
\text { Estatístico }\end{array}$ & Resultado \\
\hline $\mathrm{H} 1$ & $\begin{array}{l}\text { Existe relação entre endividamento e investimentos em inovação } \\
\text { tecnológica. }\end{array}$ & \multirow{5}{*}{$\begin{array}{l}\text { Correlação e } \\
\text { Regressão } \\
\text { Linear } \\
\text { Múltipla }\end{array}$} & Rejeitada \\
\hline $\mathrm{H} 2$ & $\begin{array}{c}\text { Existe relação entre capacidade de pagamentos de dívida e } \\
\text { investimentos em inovação tecnológica. }\end{array}$ & & Aceita \\
\hline $\mathrm{H} 3$ & $\begin{array}{l}\text { Existe relação entre composição de dívida e investimentos em } \\
\text { inovação tecnológica. }\end{array}$ & & Rejeitada \\
\hline $\mathrm{H} 4$ & $\begin{array}{l}\text { Existe relação entre custo do capital de terceiros e investimentos } \\
\text { em inovação tecnológica. }\end{array}$ & & Aceita \\
\hline H5 & $\begin{array}{c}\text { Existe relação entre grau de participação em subsidiárias e } \\
\text { investimentos em inovação tecnológica. }\end{array}$ & & Aceita \\
\hline H6 & Existe relação entre endividamento e geração de patentes. & \multirow{5}{*}{$\begin{array}{c}\text { Teste de } \\
\text { Kruskal- } \\
\text { Wallis }\end{array}$} & Rejeitada \\
\hline $\mathrm{H} 7$ & $\begin{array}{l}\text { Existe relação entre capacidade de pagamentos de dívida e } \\
\text { geração de patentes. }\end{array}$ & & Rejeitada \\
\hline $\mathrm{H} 8$ & Existe relação entre composição de dívida e geração de patentes. & & Rejeitada \\
\hline H9 & $\begin{array}{c}\text { Existe relação entre custo do capital de terceiros e geração de } \\
\text { patentes. }\end{array}$ & & Rejeitada \\
\hline H10 & $\begin{array}{l}\text { Existe relação entre grau de participação em subsidiárias e } \\
\text { geração de patentes. }\end{array}$ & & Rejeitada \\
\hline
\end{tabular}

Quadro 4 - Síntese dos testes de hipóteses.

Fonte: Elaborado pelos autores, 2013.

Em relação à análise do relacionamento entre os outputs (patentes) do processo de inovação tecnológica e estrutura de capital nas empresas, o resultado encontrado foi o mesmo para todas as 
Emmanuel Sousa de Abreu, Adriano Leal Bruni, Sonia Maria da Silva Gomes \& Roberto Brazileiro Paixão

variáveis envolvidas na pesquisa. Ou seja, as hipóteses instrumentais H6 H7 H8 H9 e H10 estabelecidas obtiveram o mesmo resultado.

Cabe ressaltar que o trabalho mais próximo encontrado na literatura que avalia a relação entre patentes e estrutura de capital em ambiente brasileiro é o de Kayo et al. (2004). Os autores encontraram um relacionamento negativo e significativo entre indicadores de patentes e endividamento. Com resultados diferentes, a presente pesquisa não encontrou relações significantes entre estrutura de capital e patentes, porém, em sintonia com o achado, os resultados indicaram que o grupo com elevado índice de patentes apresentou menor média de posição em relação ao indicador de endividamento geral, o que reforça o achado dos autores, apesar da diferença não ter tido significância estatística.

Quanto à análise da relação entre esforço de inovação e estrutura de capital, obtiveram-se, como se esperava, diferentes resultados, tendo sido encontradas relações entre alguns indicadores de estrutura de capital e investimentos em P\&D.

Desse forma, os resultados encontrados em trabalhos empíricos como os de Aghion et al. (2004) e Hovakimian et al. (2001) que sugerem que a alavancagem é negativamente relacionada aos gastos em $\mathrm{P} \& \mathrm{D}$, não puderam ser validados pela presente pesquisa, provavelmente em virtude das peculiariedades existentes no ambiente brasileiro. As dificuldades de monitoramento de $\mathrm{P} \& \mathrm{D}$, a assimetria informacional, a incerteza, e o potencial desalinhamento de interesses entre os proprietários e os financiadores não parecem explicar a estrutura de capital em empresas brasileiras de capital aberto com elevado índice de P\&D.

É importante esclarecer que o resultado não significativo encontrado para as variáveis endividamento geral e composição do endividamento pode ser justificado em ambientes em que a necessidade de financiamento de P\&D por meio de recursos internos é amenizada em virtude de fontes de financiamento alternativas ao mercado convencional, como parece ser o caso brasileiro em que o processo de financiamento é suportado em grande parte com apoio governamental.

Essa característica do ambiente brasileiro é trazido por Valle (2008) que ressalta que, apesar das difíceis condições existentes, as empresas brasileiras tiveram oportunidade de se financiar a partir de fontes diferenciadas de recursos com taxas de juros exclusivas, como são as linhas do BNDES. No mesmo sentido, Meirelles (2008) ao caracterizar os aspectos financeiros do processo de inovações tecnológicas também deu destaque ao financiamento e aos mecanismos financeiros de incentivo governamental para a realização de investimentos em atividades inovativas na indústria brasileira.

Outra explicação para o resultado encontrado é apontada no trabalho de Magri (2009) que mostrou evidências de que as pequenas empresas inovadoras se endividam menos e tendem a utilizar

Revista de Administração e Inovação, São Paulo, v.12, n.1, p.326-350, jan./mar. 2015. 
mais recursos financeiros próprios, mas que em grandes empresas, as diferenças não são significativas. O menor impacto das restrições às empresas de grande porte também são relatados por Hall (2002), que já tinha relatado em seu trabalho que evidências da existência de restrições de financiamento de P\&D para grandes empresas são mais difícies de serem estabelecidas.

Como no presente trabalho, a amostra foi formada por empresas brasileiras de capital aberto, o porte das companhias também é elevado o que tende a amenizar o efeito das restrições financeiras impostas. Em adição a esse aspecto, a amostra restrita utlizada nesta pesquisa também pode não ter possibilitado o encontro de resultados significativos, evidenciado a importância da construção no país de meios de acesso mais amplos a dados sobre inovação tecnológica.

Apesar de não ter sido verificada a relação entre alavancagem e composição da dívida com os gastos em $\mathrm{P} \& \mathrm{D}$, outros aspectos ligados à restrição financeira e aos investimentos de empresas com alto índice de inovação foram revelados. Destaca-se o resultado encontrado de que empresas com maiores esforços em $\mathrm{P} \& \mathrm{D}$ tendem a terem custo de captação de capital com terceiros menores. Esse resultado aparentemente é paradoxal com a informação trazida pelo relatório do IBGE (2010) de que o elevado custo do processo de inovação se caracteriza como principal obstáculo à inovação em empresas industriais brasileiras, se o raciocínio utilizado for um silogismo direto inadequado como: se as empresas que mais investem em inovação, são aquelas que tem menores custos, então investir em inovação faria reduzir os custos de captação. Dessa forma, aparentemente, poderia se refutar a existência de restrições financeiras a empresas inovadoras.

A evidência, contudo, tem aderência com as características do ambiente brasileiro e com a outra relação significativa encontrada no presente trabalho, a de que o grau de cobertura da dívida tende a ser mais elevado com os gastos em inovação tecnológica. Explicando melhor, a partir do momento que as dificuldade do processo inovativo (incerteza, intangibilidade, e difícil apropriação) imporiam altas restrições às empresas, é razoável se entender que os custos impostos tenderiam a possibilitar que somente empresas com capacidade de endividamento, ou acesso a recursos diferenciados ou governamentais possam investir em processos de inovação. Observe-se que a análise se ajusta a visão de que as características da estrutura de capital de uma empresa determinam o processo de inovação, e, não, o inverso como encontrado em contextos como os dos estudos de Geronikolaou e Papachristou (2008) e o de Ueda e Hirukawa (2003).

De outra forma, o investimento em inovação no Brasil teria um viés de oportunidade, acontecendo apenas em situações específicas em que as empresas têm acesso a recursos mais atraentes, ou então em virtude de apoio governamental. A possibilidade de investimento em P\&D estaria restrita no Brasil à empresas com alta capacidade financiamento e àquelas com acesso a recursos com taxas

Revista de Administração e Inovação, São Paulo, v.12, n.1, p.326-350, jan./mar. 2015. 
Emmanuel Sousa de Abreu, Adriano Leal Bruni, Sonia Maria da Silva Gomes \& Roberto Brazileiro Paixão

diferenciadas. Esse argumento é reforçado pelo estudo de Costa e Deos (2002) que destacam o financiamento indireto (setor público e externo) e direto (autofinanciamento) como as duas alternativas de financiamento de recursos a termo no Brasil, o que vai ao encontro dos resultados encontrados por Albuquerque e Sicsú (2000).

A importância significativa dessas fontes de recursos diferenciadas e das linhas em moeda estrangeira para as empresas brasileiras também foi evidenciada por Valle (2008) e por Meirelles (2008) que destacaram especificamente o financiamento e os mecanismos financeiros de incentivo governamental no processo de implementação de inovações tecnológicas na indústria brasileira.

Dessa forma, as correlações entre as variáveis Ebdb (cobertura da dívida) e Cct (custo do capital de terceiros) com a variável Ped (Gastos em P\&D) se ajustam bem às características do processo de financiamento à inovação tecnológica em nível nacional. A primeira variável demonstra como a maior capacidade de pagamento das dívidas com terceiros pelas companhias brasileiras lhe conferem a propensão de investir mais em P\&D. No mesmo sentido, a segunda variável aponta como os gastos em P\&D tendem a aumentar à medida que as despesas médias destinadas à remuneração do capital de terceiros diminuem.

Especificamente em relação à correlação entre as variáveis Ebdb (cobertura da dívida) e a variável Ped (Gastos em P\&D), o resultado vai ao encontro do esperado pela literatura internacional, pois sugere que empresas com maior capacidade de geração de recursos internos tendem a investir mais em P\&D. Assim, a correlação positiva entre investimento em $\mathrm{P} \& \mathrm{D}$ e financiamento via recursos internos apontados por trabalhos como os de Himmelberg e Petersen (1994), Harhoff (1998) e Bond et al. (2003) parece também existir em ambiente brasileiro, pelo menos dentro do segmento estudado.

A capacidade de cobertura da dívida e o custo do capital de terceiros também tiveram destaque no presente trabalho em virtude da capacidade de predição dos gastos em P\&D de empresas brasileiras de capital aberto em setores com alto potencial inovativo. É importante destacar, contudo, que não se tem o intuito de que os fatos evidenciados se repitam exatamente, como os resultados típicos das ciências exatas. Parece ser claro que estudos relacionados à inovação tecnológica e estrutura de capital estão sujeitos aos mais complexos e diversos eventos, sejam eles de natureza social, política ou econômica. O modelo empírico produzido, contudo, permite identificar tendências e relações que possibilitam o melhor entendimento do grau de relacionamento entre as variáveis, permitindo-se inferir perspectivas e resultados a depender de como ocorra os fatos sociais em situações futuras.

De forma complementar, ainda foi verificado a existência de correlação negativa entre a variável grau de investimento e a variável gastos em P\&D. A relação indicou que existe uma tendência

Revista de Administração e Inovação, São Paulo, v.12, n.1, p.326-350, jan./mar. 2015. 
de que empresas com relevantes participações em outras sociedades tenham menores investimentos em P\&D.

\section{LIMITAÇÕES, CONSIDERAÇÕES FINAIS E SUGESTÕES PARA NOVOS ESTUDOS}

As principais limitações do presente trabalho estão relacionadas com a amostra e com as opções epistemológicas utilizadas na pesquisa. A clareza dessas limitações são de fundamental importância para que se possa compreender e delimitar os reais alcances dos resultados encontrados, não se incorrendo em erros advindos de silogismos inadequados, principalmente quando da análise de pesquisas probabilisticas baseadas em amostras obtidas por disponibilidade e com natureza positivista.

Os limites impostos pela amostra utilizada se devem a dificuldade de acesso no ambiente brasileiro de informações abrangentes sobre inovação tecnológica, sendo essa uma das maiores dificuldades enfrentada pelos pesquisadores brasileiros que atuam com essa linha de pesquisa. Esse obstáculo se torna ainda maior quando se tem o objetivo de análisar objetivamente relações ao nível da firma o que impõe a utilização de microdados ${ }^{2}$. Assim, os resultados não significativos encontrados não implicam em inexistência de relação entre as variáveis, como foram exemplos as relações entre endividamento geral e os gastos com $\mathrm{P} \& \mathrm{D}$ ou as relações entre patentes e os indicadores de estrutura de capital.

A falta de significância encontrada nos casos observados nessa pesquisa pode ser interpretada como a falta de evidências das relações inicialmente propostas, mas não como a falta de relação entre as variáveis. Até mesmo as hipóteses confirmadas nessa pesquisa não devem ser traduzidas como provas dos relacionamentos das variáveis, mas apenas como a existência de um relacionamento provável, e isso, restritamente no âmbito do universo utilizado, ou seja, o de empresas brasileiras de capital aberto em ramos com potencial de inovação tecnológica, conforme definido na Seção 3.

Os limites metodológicos fazem parte de qualquer trabalho científico, principalmente nas ciências sociais aplicadas como é o caso das ciências voltadas para a area de gestão organizacional. No

\footnotetext{
${ }^{2}$ Inicialmente o presente trabalho buscou agregar dados da PINTEC, porém as duas solicitações de dados ao IBGE, uma de informações agregadas desindentificadas, outra de acesso à sala de sigilo da instituição, foram negadas com justificativas vagas que revelaram a indisponibilidade de dados de grandes empresas pela pesquisa, demonstrando a fragilidade da amostra e dos dados divulgados pela PINTEC. Outras informações podem ser obtidas por meio de consulta aos processos: IBGE 03605.000665/2013-25 e IBGE 03605.000196/2013-44.
} 
presente artigo, parte-se da noção tradicional de inovação como um processo linear, no qual existem insumos (inputs) e saídas (outputs), a partir de um modelo simplificado da natureza do processo inovativo. Dessa forma, os achados da presente pesquisa devem ser avaliados e entendidos em conjunto com diferentes pesquisas, inclusive de natureza descritiva e qualitativa, não se limitando a uma simples correlação entre dados.

As próprias métricas de inovação utilizadas na presente pesquisa são classificadas por Figueiredo (2005) como "indicadores convencionais”, que lista algumas de suas limitações, que são, em suma: a) os indicadores seriam significativos apenas em alguns setores industriais de países tecnologicamente avançados; b) empresas que operam em economias em desenvolvimento não costumam deter laboratórios de P\&D formalmente estruturados; c) os indicadores "convencionais" não captariam "as características e os elementos do tecido organizacional, no qual a capacidade tecnológica é desenvolvida, acumulada e sustentada."; e d) a análise dos indicadores ficaria restrita a determinado tempo estático.

Apesar das limitações destacadas por Figueiredo (2005), o próprio autor esclarece que trabalhos que utilizam medidas quantitativas para mensurar a capacidade tecnológica são meritórios por apresentarem uma pespectiva agregada das atividades tecnólogicas em empresas brasileiras. É preciso destacar, adicionalmente, que a forma de mensuração de fatos sociais depende, principalmente, do escopo da pesquisa e que a escolha epistemológica por simplificações do mundo real são acompanhadas por um aumento da objetividade e da falseabilidade, características necessárias a determinados achados científicos em pesquisas de natureza positivista.

Outra questão que merece destaque, referente à restrição metodológica, é que esta pesquisa se utilizou fundamentalmente de modelos lineares, o que simplifica a natureza das relações existentes dentro do processo de inovação tecnológica, restringindo a sua capacidade de apontar relações significativas que não se comportam linearmente. Isso indica a necessidade de pesquisas com modelos diferenciados e, logo, também a construção de bases de dados robustas que viabilizem esse tipo de investigação.

Em virtude dos resultados encontrados, dos limites apontados e da insuficiência de estudos existentes dentro dessa linha de pesquisa, revelam-se outras questões oportunas para futuras pesquisas, destacando-se: a) investigações que avaliem o relacionamento entre estrutura de capital e inovação tecnológica a partir de modelos não-lineares; b) estudos de caso que verifiquem aspectos qualitativos das decisões de financiamento de processos de inovação tecnológica; c) analises que verifiquem a precedência temporal (causalidade) entre estrutura de capital e inovação tecnológica; e d) exames da 
existência de relações diferenciadas entre estrutura de capital e inovação tecnológica entre diferentes segmentos, portes e setores de atividade.

Espera-se que esse artigo possa contribuir para os estudos relacionados aos processos de financiamento do desenvolvimento de inovação tecnológica e de formação das estruturas de capital em empresas brasileiras.

\section{REFERÊNCIAS}

Aghion, P. et al. (2004). Technology and financial structure: are innovative firms different?. Journal of European Economic Association, v. 2, p. 277-288.

Albuquerque, E. M. \& Sicsú, J. (2000). Inovação institucional e estímulo ao investimento privado. São Paulo Perspectiva, São Paulo, v.14, n. 3.

Arrow, K. J. (1962). Economic welfare and the allocation of resources for invention. In: Nelson, R. R. (Eds.). The rate and direction of inventive activity: economic and social factors. Princeton: National Bureau of Economic Research/Princeton University Press, 1962.

p. 609-626.

Bartoloni, E. (2010). Capital structure and innovation: causality and determinants. Paper to be presented at the Summer Conference.

Blass, A. A. \& Yosha, O. (2003). Financing R\&D in mature companies: an empirical analysis. Economics of Innovation and New Technology, v. 12, p. 425-447.

Bond, S.; Harhoff, D. \& Reenen, J. V. (2003). Investment, $R \& D$ and finacial constraints in Britain and Germany. London: The Institute for Fiscal Studies, Mimeografado. (Working Paper Series, $\mathrm{n}$. W99/5).

Bond, S. \& Reenen, J. V. (1999). Microeconometric models of investment and employment. London: The Institute for Fiscal Studies. Mimeografado.

Lei $n^{\circ} 11.196$, de 21 de novembro de 2005. (2005). Institui o regime especial de tributação para a plataforma de exportação de serviços de tecnologia da informação - REPES, o regime especial de aquisição de bens de capital para empresas exportadoras - RECAP e o Programa de Inclusão Digital; dispõe sobre incentivos fiscais para a inovação tecnológica, entret al.. Brasília, DF. Recuperado em: <http://www.planalto.gov.br/ccivil_03/leis/L11196.htm>. Acesso em: 12 jan. 2012.

Brown, W. (1997). $R \& D$ intensity and finance: are innovative firms financially constrained? Londres: London School of Economics, Financial Market Group. Artigo para discussão.

Costa, F. N. \& Deos, S. S. (2002). Reflexões sobre o financiamento na economia brasileira. Campinas: IE/UNICAMP, (Texto para discussão, n. 109). 
Emmanuel Sousa de Abreu, Adriano Leal Bruni, Sonia Maria da Silva Gomes \& Roberto Brazileiro Paixão

Crocco, M., Cavalcante, A. T. \& Brito, M. L. A.; Albuquerque, E. M. (2008). Patentes e sistemas financeiros: um estudo exploratório para o Brasil. Revista Brasileira de Inovação,

Rio de Janeiro, v.7, n.2, p.367-407, julho/dezembro.

De Negri, J. A. \& Freitas, F. (2004). Inovação tecnológica, eficiência de escala e exportações brasileiras. Brasília: IPEA. (Texto para discussão, n. 1.044).

Dosi, G., Pavitt, K. \& Soete, L. (1990). The economics of technical change and international trade. Londres: Harvester Wheatsheaf.

Figueiredo, P. N. (2005). Acumulação tecnológica e inovação industrial: conceitos, mensuração e evidências no Brasil. São Paulo em Perspectiva, v. 19, n. 1, p. 54-69.

Geronikolaou, G., \& Papachristou, G. (2008). Venture capital and innovation in Europe. Grecia: University of Thessaloniki. (Working papers ). Recuperado em: 〈http://ssrn.com/abstract=1309186 $>$. Acesso em: 12 jan. 2012.

Hall, B. (2002). The financing of research and development. Oxford Review of Economic Policy, v. 18, p. $35-51$.

Harhoff, D. (1998). Are there financing constraints for R\&D and investment in German manufacturing firms?. Annales d'Économie et de Statistique, n. 49/50, p. 421-456.

Himmelberg, C. P., \& Petersen, B.C. (1994). R\&D and internal finance: a panel study of small firms in High-Tech Industries. Review of Economics and Statistics, v. 76, p. 38-51.

Hovakimian, A., Opler, T., \& Titman, S. (2001). The debt-equity choice. Journal of Financial and Quantitative Analysis, v. 36, p. 1-24.

IBGE. (2004). Pesquisa industrial de inovação tecnológica - PINTEC. Rio de Janeiro: IBGE. (Série relatórios metodológicos, v. 30).

Jensen, J., Menezes-Filho, N., \& Sbragia, R. (2004). Os determinantes dos gastos em P\&D no Brasil: uma análise com dados em painel. Estudos Econômicos, v. 34, n.4, p. 661-691.

Kaufmann, A., \& Todtling, F. (2002). How effective is innovation support for SMEs? an analysis of the region of Upper Austria. Technovation, v. 22, p. 147-159.

Kayo, E. K. (2002). A estrutura de capital e o risco das empresas tangível e intangível-intensivas: uma contribuição ao estudo da valoração de empresas. 2002. Tese (Doutorado em Administração) FEA/USP.

Kayo, E. K., Teh, C. C., \& Basso, L. F. C. (2004). A influência dos ativos intangíveis sobre a estrutura de capital. In: ENCONTRO DA ANPAD, 28., Curitiba, 2004. Anais... Rio de Janeiro: ANPAD.

Klette, T. J., \& Gliliches, Z. (2000). Empirical patterns of firm growth and R\&D investment: a quality ladder model interpretation. The Economic Journal, v. 110, p. 363-387.

Revista de Administração e Inovação, São Paulo, v.12, n.1, p.326-350, jan./mar. 2015. 
Koschatzky, K. (1999). Innovation networks of industry and business-related services - relations between innovation intensity of firms and regional inter-firm cooperation. European Planning Studies, v. 7, n. 6, p. $737-757$.

Kruskal, W. H. (1952). A nonparametric test for the several sample problem. Annals of Mathematical Statistics, v. 23, n. 4, p. 525-540.

Li, H., \& Atuahene-Gima, K. (2001). Product innovation strategy and the performance of new technology ventures in China. Academy of Management Journal, v. 44, n. 6, p. 1123-1134.

Madrid-Guijarro, A., Garcia, D., \& Van Auken, H. (2009). Barriers to Innovation among Spanish Manufacturing SMEs. Journal of Small Business Management, v. 47, p. 465-488.

Magri, S. (2009). The financing of small innovative firms: the Italian case. Economics of Innovation and New Technology, v.18, n. 2, p. 181-204.

Meirelles, J. L. F. (2008). Inovação tecnológica na indústria brasileira: investimento, financiamento e incentivo governamental. Tese ( Doutorado em....) - FEA/USP, São Carlos.

Motohashi, K. (1998). Innovation strategy and business performance of Japanese manufacturing firms. Economics of Innovation and New Technology, v. 7, n. 1, p. 27-52.

Nakamura, W. T. et al. (2007). Determinantes de estrutura de capital no mercado brasileiro: análise de regressão com painel de dados no período 1999-2003. Revista Contabilidade e Finanças, São Paulo, n. 44, p. $72-85$.

Organization for Economic Co-operation and Development- OECD. (2006). Manual de Oslo diretrizes para coleta e interpretação de dados sobre inovação. Brasília.

Radas, S. ; Bozic, L. (2009). The antecedents of SME innovativeness in an emerging transition economy. Technovation, v. 29, p. 438-450.

Rothwell, R. (1994). Towards the fifth-generation innovation process. International Marketing Review, v. 11, n. 1, p. 7.

Sbragia, R. (1999). Los indicadores de I, D\&E en las empresas mas y menos innovadoras. Spacios, Revista Venezuelana de Gestion Tecnologica, v. 120, n. 1.

Sbragia, R., Kruglianskas, I., \& Arango-Alzate, T. (2003). Empresas inovadoras no Brasil: uma proposição de tipologia e características associadas. São Paulo: Universidade de São Paulo.

Schumpeter, J. A. (1997). Teoria do desenvolvimento econômico: uma investigação sobre lucros, capital, crédito, juro e ciclo econômico. Tradução de Maria Silvia Passos. São Paulo: Nova Cultural. Material em pdf.

Sicsú, J. E., \& Albuquerque, E. (2002). O papel de uma Agência Especial de Seguros de Empréstimos no Brasil. Revista Brasileira de Economia, v. 22, n. 2.

Soete, L., \& Weel, B. (1999). Schumpeter and the knowledge-based economy: on technology and competition policy.

Revista de Administração e Inovação, São Paulo, v.12, n.1, p.326-350, jan./mar. 2015. 
Tidd, J. (2001). Innovation management in context: environment, organization and performance. International Journal of Management Reviews, v. 3, n. 3, p. 169-183.

Tidd, J., Bessant, J., \& Pavitt, K. (2005). Managing innovation: integrating technological, market and organizational change. 3. ed. Canada: John Wiley.

Ueda, M., \& Hirukawa, M. (2003). Venture capital and productivity. Wisconsin, USA: University of Wisconsin, USA. (Working paper). Recuperado em: <http://www.math.niu.edu/ hirukawa/papers/VCAP4.pdf>. Acesso em: 20 jan. 2012.

Valle, M. R. do. (2008). Estrutura de capital de empresas brasileiras num ambiente de altas taxas de juros e na presença de fontes diferenciadas de financiamento. Tese (Livre Docência) - FEA-RP/USP, Ribeirão Preto.

Walker, R. M. et al. (2002). Measuring innovation - applying the literature based innovation output indicator to public services. Public Administration, v. 80, n. 1, p. 201-214.

\begin{abstract}
The funding process for innovative projects is a relevant and peculiar subject due to its high levels of intangibility tendence, hard ownership and high information asymmetry that confer high risks and costs to organizations. In this way, the present study shows the existence of relationships between variables of capital structure and technological innovation in Brazilian environment, from the assumptions of the linear innovation model. The research analysis universe involved publicly traded companies of Information Technology, Quemistry, Telecommunications and Industrials goods. Different statistical procedures were applied, such as the multiple linear regression analysis and Kruskal-Wallis non-parametric test. For the input variable, were found significant correlations between R\&D spendings and payments capacity, capital cost and investment in subsidiaries. Regarding the output variables, it was not possible to verify the relationship between innovation and capital structure. The evaluation of the results shows that there seems to be a direct link between capital structure and innovation input connected to financial efforts, but that the innovation output, a priori, or does not have the same strength in the indicators of capital structure relation, or presents more tenuous relationship. The different results shows that the linear model works as a simplification of the real world, that enables partial quantitative assessments, but, in the other hand, that interactive models seems to be more consistent when don't linearly link effort in research with innovation processes results.
\end{abstract}

Keywords: Technological innovation; Capital structure; Research and development; Patents.

Data do recebimento do artigo: 16/06/2014

Data do aceite de publicação: 14/02/2015

Revista de Administração e Inovação, São Paulo, v.12, n.1, p.326-350, jan./mar. 2015. 